\title{
Wykorzystanie logiki rozmytej w badaniach petrofizycznych
}

\begin{abstract}
Praca ta stanowi próbę wprowadzenia logiki rozmytej (ang. fuzzy logic) do zagadnień petrofizycznych. Logika rozmyta jest metodą zasadniczo różniącą się od innych metod obliczeniowych, takich jak np. sieci neuronowe. Przede wszystkim operuje na zbiorach rozmytych, wykorzystując wyrażenia lingwistyczne oraz rozmyte zależności i rozmyte reguły postępowania. W pracy przedstawiono działanie schematu obliczeniowego zwanego sterownikiem rozmytym, zastosowanego do parametrów opisujących właściwości skał. Przeprowadzono obliczenia pozwalające przetestować metodę, wyliczając porowatość na bazie zestawu innych parametrów. Skuteczność metody pokazano poprzez zestawienie z wynikami rzeczywistymi. Korelacja była zadowalająca, wynosiła powyżej 0,840 - nawet do 0,880 dla pełnego zbioru danych.
\end{abstract}

Słowa kluczowe: logika rozmyta, regulator rozmyty, funkcje przynależności, stopnie przynależności.

\section{The use of fuzzy logic in petrophysical studies}

\begin{abstract}
This work is an attempt to introduce fuzzy logic to petrophysical problems. Fuzzy logic improved by Zadeh in 1965, unlike other mathematical methods like classical logic or neural network, is based on fuzzy sets with the use of fuzzy rules, linguistic variables and fuzzy connections. Descriptions of this method are shown in the paper. The work of the fuzzy controller was demonstrated. Experiments were carried out with the use of petrophysical parameters. The efficiency of this method was shown by a comparison between the real and obtained data. The correlation coefficient was over 0.840 - even up to 0.880 for a full set of data.
\end{abstract}

Key words: fuzzy logic, fuzzy controller, membership functions, membership degrees.

\section{Wstęp}

Praca jest próbą zastosowania logiki rozmytej (ang. fuzzy logic) do zagadnień petrofizycznych przy definiowaniu takich zjawisk jak przestrzeń porowa skał czy przepuszczalność. Do tego celu posłużono się właśnie metodą logiki rozmytej, której podstawowe zasady zostały zaprezentowane we wcześniejszych publikacjach $[1,2]$. W zacytowanych pracach przedstawiono metodę i określono skuteczność jej działania. W niniejszej publikacji zajęto się określeniem wielkości wpływu poszczególnych parametrów petrofizycznych, otrzymanych w badaniach laboratoryjnych, na porowatość. W pracy posłużono się badaniami wykonanymi przez autorki artykułu w INiG - PIB, w Zakładzie Geologii i Geochemii, w Pracowni Petrofizyki. Wykonano 95 analiz porozymetrycznych przy użyciu aparatu AutoPore firmy Micromeritics i piknometrii helowej na aparacie AccuPyc firmy Micromeritics, na próbkach skalnych dobranych tak, by reprezentowały szeroki zakres parametrów petrofizycznych. Na podstawie otrzymanych danych próbowano określić wagę poszczególnych parametrów w analizie przestrzeni porowej skał.

\section{Podstawowe pojęcia i terminy stosowane w logice rozmytej}

Należy przypomnieć, o czym autorki pisały już w swoich wcześniejszych pracach [1,2], że logika rozmyta jest, podob- nie jak sieci neuronowe, techniką obliczeniową, niemniej jednak opartą na odmiennych zasadach. O ile sieci neuronowe 
są matematycznym odwzorowaniem biologicznych oddziaływań w systemie nerwowym, to logika rozmyta, wprowadzona przez Zadeha w 1965 roku, opiera się wprawdzie na wzorcach matematycznych, a szczególnie logiki klasycznej, ale dalej podobieństwo zmierza w inną stronę. Logika rozmyta wykorzystuje teorię zbiorów rozmytych i zasad rozmytego rozumowania [11]. Od logiki klasycznej różni ją zastosowanie nieostrych granic zbiorów i nieostrych wartości. Oznacza to, że stopnie przynależności przyjmują nie tylko stany zero-jedynkowe, jak w logice klasycznej, ale też stany pośrednie $0<x<1$. Wprowadzone też zostało pojęcie zmiennej lingwistycznej, co jest najbardziej nowatorskie w tej technice obliczeniowej $[5,7,10,11]$.
W porównaniu z innymi metodami obliczeniowymi, takimi jak sieci neuronowe czy analiza skupień albo też logika klasyczna, z której wywodzi się omawiana metoda, logika rozmyta nie opiera się na utworzeniu algorytmów w ściśle matematycznym rozumieniu, stosujących ściśle określone (tak zwane ostre) pojęcia. Logika rozmyta opiera się na wyrażeniach lingwistycznych oraz rozmytych zależnościach i rozmytych regułach postępowania. Wychodząc ze świata liczb ostrych, przekształca się je w zbiory rozmyte, za pomocą rozmytych narzędzi przekształcających i reguł rozmytych (funkcje i stopnie przynależności oraz normy), aby na koniec przez funkcje wyostrzania powrócić do liczb ostrych $[6,8,9]$. Taka jest zasada rozmytego systemu wnioskującego.

\section{Rozmyty system wnioskujący}

Powyższe zasady znajdują zastosowanie w rozmytych systemach wnioskujących. Schemat takiego systemu (zwanego też sterownikiem rozmytym) został przedstawiony na rysunku 1 .

$$
\mu_{A^{\prime}}(x)=\left\{\begin{array}{l}
1, \text { jeżeli } x=x^{\prime} \\
0, \text { jeżeli } x \neq x^{\prime}
\end{array}\right.
$$

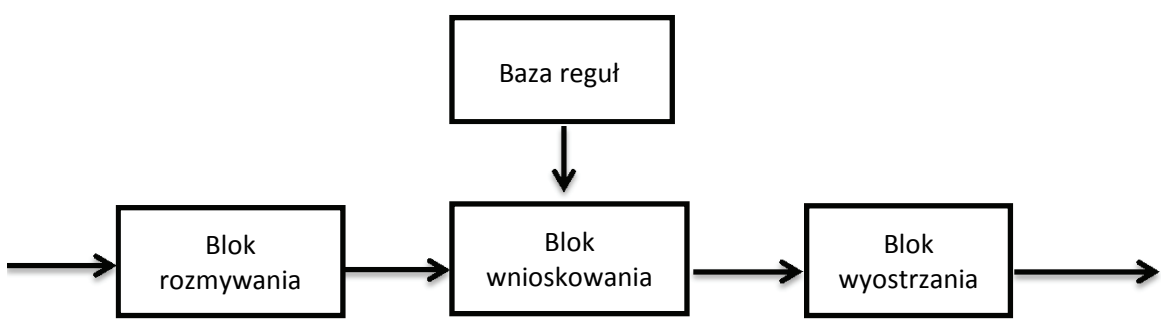

Rys. 1. Schemat blokowy sterownika rozmytego
Blok wnioskowania

Rozmyte zbiory poddawane są regułom wnioskowania. Baza reguł wnioskowania zwana też bywa modelem lingwistycznym. Opiera się na wnioskowaniu typu: JEŻELI... TO... Istnieje wiele reguł wnioskowania dla modelu logicznego z wykorzystaniem implikacji rozmytej, można je znaleźć w literaturze $[5,6,7,10]$.

Konkretna postać funkcji przyporząd-
Poszczególne bloki to kolejne kroki w przekształcaniu danych na sposób rozmyty.

\section{Blok rozmywania}

Blok rozmywania pozwala konkretną wartość ze zbioru rzeczywistego $x=\left(x_{1}, x_{2}, x_{3}, \ldots x_{n}\right)$ należącą do $X$ przekształcić w procesie rozmywania (ang. fuzzification) w zbiór rozmyty $A^{\prime} \subseteq X=X_{1} \cdot X_{2} \cdot \ldots \cdot X_{i} \cdot \ldots \cdot X_{n}$, gdzie $A$ ' jest zbiorem rozmytym, a $X_{i}$ stanowią przestrzenie zmiennych wejściowych. Przy czym stosuje się tu operację rozmywania typu singleton zdefiniowanego we wzorze (1): kowania $\mu$ zależy od przyjętej normy trójkątnej, reguły wnioskowania oraz typu operacji na zbiorach rozmytych, co zostało nakreślone w poprzednich pracach [1, 2]. Poniżej przedstawiono założenia funkcji przynależności, którą opisuje zależność:

$$
\mu_{A \rightarrow B}(x, y)=T\left(\mu_{A}(x), \mu_{B}(y)\right)
$$

jednej z częściej stosowanych reguł wnioskowania: regułę typu minimum. W modelu tym, gdzie rozmyta implikacja $A \rightarrow B$ funkcji przynależności $\mu_{A \rightarrow B}$ jest równoważna relacji rozmytej: $R \subseteq X \cdot Y$, a $T$ jest zastosowaną $T$-normą. Wtedy reguła typu minimum ma postać:

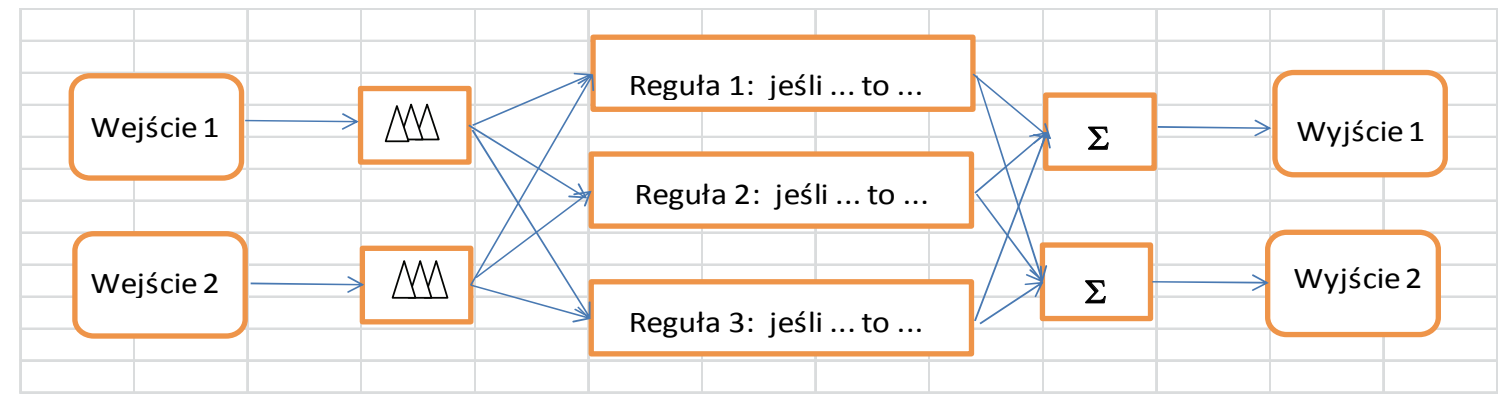

Rys. 2. Schemat blokowy doboru reguł w procesie wnioskowania 


$$
\mu_{A \rightarrow B}(x, y)=\mu_{R}(x, y)=\mu_{A}(x) \wedge \mu_{B}(y)=\min \left[{ }_{A}(x), \mu_{B}(y)\right]
$$

Rozmyty system wnioskowania zapisuje się w postaci:

$$
\begin{aligned}
& R^{k}: \text { JEŻELI } x_{1}^{k} \text { jest } A_{1}^{k} i x_{2}^{k} \text { jest } A_{2}^{k} i \ldots i x_{n}^{k} \text { jest } A_{n}^{k} \\
& \text { TO } y^{k} \text { jest } B^{k}
\end{aligned}
$$

gdzie: $x_{1}^{k}, x_{2}^{k}, \ldots, x_{n}^{k}, y^{k}$ są zmiennymi lingwistycznymi, natomiast $A_{1}^{k}, A_{2}^{k}, \ldots, A_{n}^{k}, B^{k}$ są wartościami lingwistycznymi, którym odpowiadają zbiory rozmyte $\mathcal{A}_{1}^{k}, \mathcal{A}_{2}^{k}, \ldots, \mathcal{A}_{n}^{k}, \mathcal{B}^{k}$.

\section{Blok wyostrzania}

Stosując powyższe reguły wnioskowania, dochodzimy do momentu, gdy na wyjściu pojawia się rozwiązanie, czyli wniosek, w zależności od zaprojektowanego zadania, w postaci jednego lub więcej zbiorów rozmytych $\mathcal{B}^{k} \mathrm{z}$ funkcjami przynależności $\mu_{B}^{k}(y), k=1,2, \ldots, N$.

W bloku wyostrzania przeprowadza się proces odwrotny do rozmywania, czyli wyostrzanie, zwane też defuzyfikacją (ang. defuzzification). Pozwala on na odwzorowanie zbiorów rozmytych w jedną ostrą wartość. Dla $N$ zbiorów rozmytych $\mathcal{B}^{k}$ ostra wartość $y ́ \in Y$ może zostać wyliczona różnymi metodami. Dwie z nich przedstawiono poniżej:

Metoda środka ciężkości (ang. center of gravity, COG)

Jest to metoda, w której wynik otrzymujemy, wyznaczając środek ciężkości ý funkcji przynależności

$$
\dot{y}=\frac{\sum_{k=1}^{N} y^{k} \mu_{B^{\prime}}\left(y^{k}\right)}{\sum_{k=1}^{N} \mu_{B^{\prime}}\left(y^{k}\right)}
$$

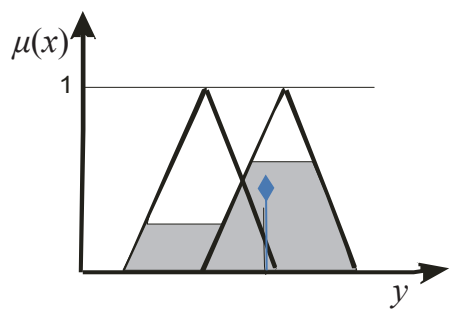

Rys. 3. Graficzne przedstawienie sensu środka ciężkości w logice rozmytej

\section{Metoda ostatniego maksimum}

W tej metodzie liczbowa wartość po wyostrzeniu wybierana jest ze zbioru wartości argumentów funkcji przynależności, dla których przyjmuje ona maksymalne wartości.

$$
\mu_{B^{\prime}}(\dot{y})=\sup \mu_{B^{\prime}}(y) y \in Y
$$

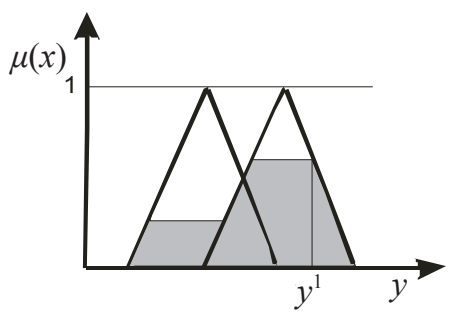

$$
\begin{aligned}
& \text { Rys. 4. Graficzne } \\
& \text { przedstawienie sensu } \\
& \text { ostatniego maksimum } \\
& \text { w logice rozmytej }
\end{aligned}
$$

W ten oto sposób na wyjściu ze sterownika rozmytego otrzymujemy oczekiwane rozwiązanie.

\section{Wykonanie przekształceń}

Przedstawiona powyżej skrótowa teoria logiki rozmytej została w praktyce użyta do oceny wielkości wpływu parametrów petrofizycznych uzyskanych w badaniach porozymetrycznych (tablica 1) na porowatość. Zgodnie z literaturą $[1,2,3,4]$ pierwszą czynnością było zaprojektowanie postępowania i dobór danych. Pole symulacji stanowiły dane uzyskane z oznaczeń porozymetrycznych i na ich podstawie zaproponowany został system kwalifikacji próbek skal- nych pod kątem ich właściwości zbiornikowych. Do obliczeń użyto danych, które w największym stopniu wiążą się z jednym z istotnych dla charakterystyki skał parametrem, czyli z porowatością. Należą do nich: różnica gęstości szkieletowej i objętościowej, średnica progowa, powierzchnia właściwa i histereza, rozumiana jako ilość rtęci, która nie została usunięta $\mathrm{z}$ próbki w procesie dekompresji, przeliczona na całkowitą ilość rtęci wtłoczonej i wyrażona w procentach.

\section{Kwalifikacja lingwistyczna}

Kolejny krok przed wykonaniem obliczeń to kwalifikacja lingwistyczna, czyli określenie granic podzbiorów lingwistycznych, które przyjęto arbitralnie. W tablicy 1 przedstawiono przypisane zakresy lingwistycznie scharakteryzowanym wielkościom.
Tablica 1. Lingwistyczne zdefiniowanie wielkości petrofizycznych

\begin{tabular}{|l|c|c|}
\hline \multicolumn{1}{|c|}{ Wielkości } & Wyrażenia lingwistyczne & Granice podzbiorów lingwistycznych \\
\hline$\Delta$ gęstości $\left[\mathrm{g} / \mathrm{cm}^{3}\right]$ & mała-średnia-duża & $0,00 \div 0,10 ; 0,04 \div 0,20 ; 0,15 \div 0,40$ \\
\hline Średnica progowa $[\mu \mathrm{m}]$ & mała-średnia-duża & $0,00 \div 5,00 ; 3,00 \div 15,00 ;>10,00$ \\
\hline Powierzchnia właściwa $\left[\mathrm{cm}^{3} / \mathrm{g}\right]$ & mała-średnia-duża & $0,00 \div 1,00 ; 0,60 \div 2,00 ;>1,50$ \\
\hline Histereza $[\%]$ & mała-średnia-duża & $0.00 \div 0,20 ; 10,00 \div 50,00 ;>35$ \\
\hline Porowatość $[\%]$ & mała-średnia-duża & $0,00 \div 5,00 ; 2,00 \div 10,00 ;>8$ \\
\hline
\end{tabular}




\section{Fuzyfikacja}

Przebieg procesów obliczeniowych zachodził zgodnie ze schematem przedstawionym na rysunku 1 , w którym pierwszym krokiem jest proces rozmywania, czyli fuzyfikacji. Posługując się funkcjami przynależności, na rysunku 5 przedstawiono przykładowo lingwistyczne rozmycie średnicy progowej, której wartość ostra wynosi $4 \mu \mathrm{m}$.

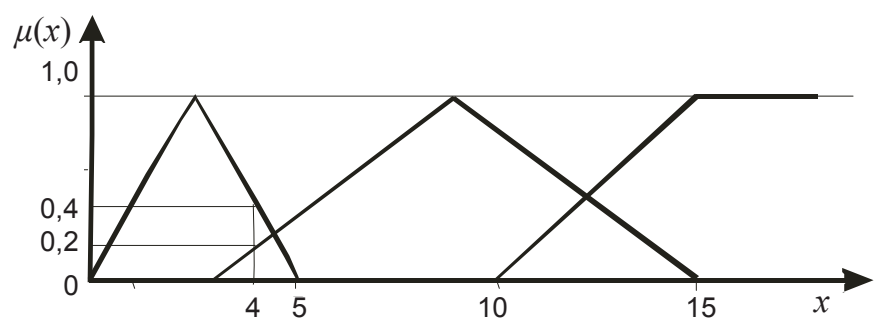

Rys. 5. Rozmywanie średnicy progowej

Zgodnie z $t$-normą uzyskujemy stopień przynależności średnicy progowej:

$$
\begin{aligned}
\mu(x) & =\min \left\{\mu_{A}{ }^{1}(x), \mu_{A}{ }^{2}(x)\right\}=x_{1}^{\mathrm{i}} / a_{1}, x_{2}^{i} / a_{2}= \\
& =0,2 / a_{1}, 0,4 / a_{2}=0,20
\end{aligned}
$$

W wyniku rozmycia otrzymujemy stopnie przynależności do zbiorów rozmytych dla ostro zadanych średnic progowych.
Podobne postępowanie przeprowadzono dla różnicy gęstości ( $\Delta$ gęstości). Rozmycie gęstości przedstawiono na rysunku 6.

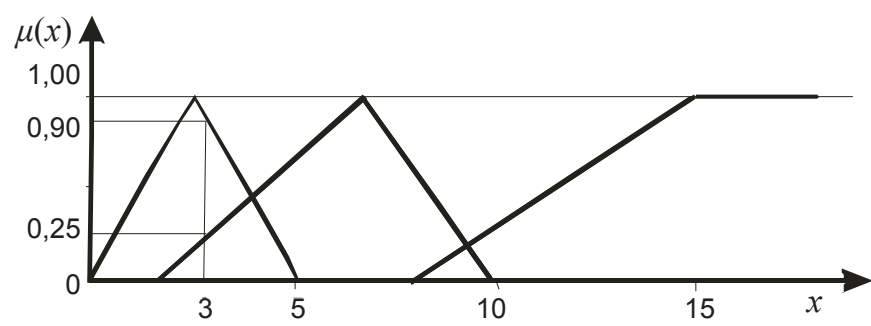

Rys. 6. Rozmywanie różnicy gęstości ( $\Delta$ gęstości)

Stopień przynależności zgodnie z $t$-normą to:

$$
\begin{aligned}
\mu(x) & =\min \left\{\mu_{B}^{1}(x), \mu_{B}^{2}(x)\right\}=x_{1}^{k} / b_{1}, x_{2}^{k} / b_{2}= \\
& =0,8 / b_{1}, 0,25 / b_{2}=0,25
\end{aligned}
$$

Zgodnie z przedstawionymi powyżej regułami rozmywania dokonano procesu rozmywania wprowadzanych wartości ostrych, stosując dobrane funkcje przynależności i określając stopień przynależności za pomocą odpowiednich norm.

$\mathrm{Z}$ pozostałymi zbiorami rozmytymi postępuje się w podobny sposób.

\section{Wnioskowanie}

Następny krok procesu (rysunek 1) to wnioskowanie typu: JEŻELI... TO... Wnioskowanie przeprowadzono na zbiorach rozmytych stworzonych na bazie schematu podanego w tablicy 2. Poniżej przedstawiono przykład wynikania dla średnicy progowej $x_{A} \mathrm{i} \Delta$ gęstości $x_{B}$ w odniesieniu do porowatości $y$ :

JEŻELI średnica progowa $\left(x_{A}\right)$ mała i $\Delta$ gęstości $\left(x_{B}\right)$ mała, TO porowatość $(y)$ mała i podobnie:

JEŻELI $x_{A}$ mała i $x_{B}$ średnia, TO $y$ mała

JEŻELI $x_{A}$ średnia i $x_{B}$ mała, TO $y$ mała

JEŻELI $x_{A}$ duża i $x_{B}$ duża, TO $y$ duża
Wykorzystując wszystkie możliwe permutacje tych wyrażeń i stosując na nich przedstawione wyżej reguły wnioskowania, uzyskujemy zbiór zwycięskich przesłanek w postaci stopni przynależności $\mu\left(x_{A}\right)$ i $\mu\left(x_{B}\right)$. Stosując wybraną normę, w tym przypadku $s$-normę, otrzymujemy zwycięski stopień przynależności:

$\mu(x)=\max \left[\mu_{A}(x), \mu_{B}(x)\right]=\max \{0,20 / a, 0,25 / b\}=0,25$

Przedstawiono tu przykładowo bardzo uproszczony model postępowania na przykładzie trzech zbiorów ostrych: średnicy progowej, $\Delta$ gęstości i porowatości.

\section{Wyostrzanie}

Proces defuzyfikacji zaprezentowano na rysunku 7. Polega on na konwertowaniu zbioru rozmytego, złożonego ze stopni przyporządkowania $\mu(x)$, do dziedziny danych wyostrzonych. W przedstawionym przypadku $\mu(x)=0,25$ lingwistycznie przyporządkowane jest do zbioru rozmytego porowatości $(0 ; 5)$, a w obliczeniach zastosowano metodę ostatniego maksimum. W efekcie przekształceń uzyskano wyostrzoną wielkość porowatości równą 4,5\%.

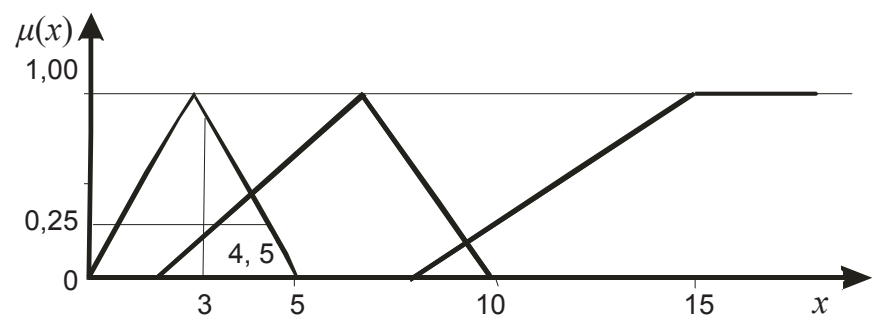

Rys. 7. Graficzna ilustracja procesu wyostrzania porowatości 


\section{Rezultaty}

Powyżej, na konkretnym przykładzie, przedstawiono zasadę zastosowanej metody. Postępowano zgodnie z nią w wykonanym zadaniu. Wykorzystano tu wszystkie zbiory ujęte w tablicy 2, które poddano omówionym wyżej regułom rozmywania i wnioskowania. W konsekwencji uzyskano zbiór stopni przyporządkowania dla każdego pojedynczego zdarzenia. W procesie wyostrzania stopnie przyporządkowania zostały przekonwertowane do rzeczywistej porowatości. Aby wyznaczyć wpływ danego parametru na porowatość, zastosowano metodę wykluczeń, tzn. określano, jaki efekt końcowy osiągnie się, wykluczając ten parametr $\mathrm{z}$ testowanego zbioru. Wyniki przedstawiono na kolejnych rysunkach. Linia niebieska stanowi zbiór porowatości rzeczywistej, czerwona -

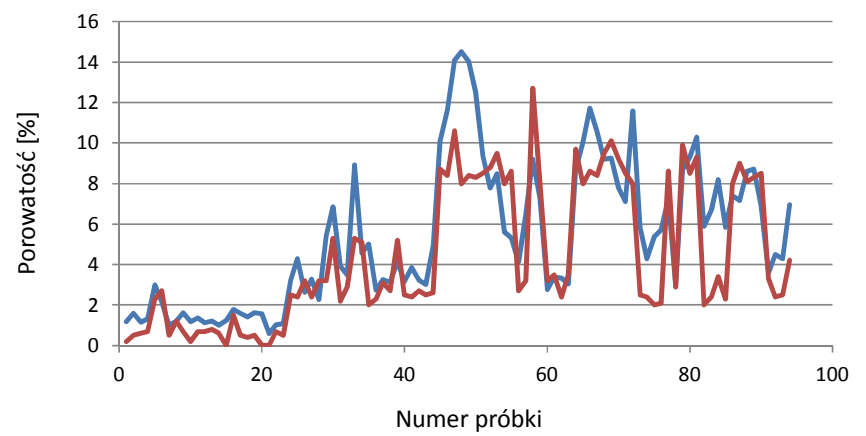

Rys. 8. Baza danych wejściowych z wykluczeniem średnicy progowej

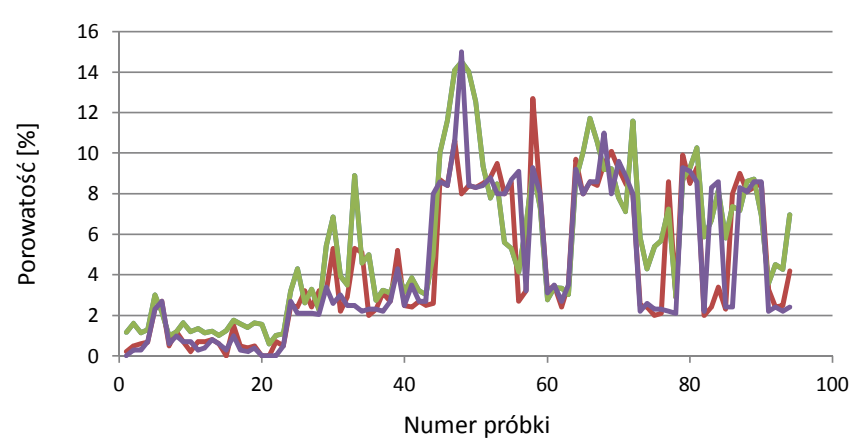

Rys. 10. Baza danych wejściowych z wykluczeniem histerezy

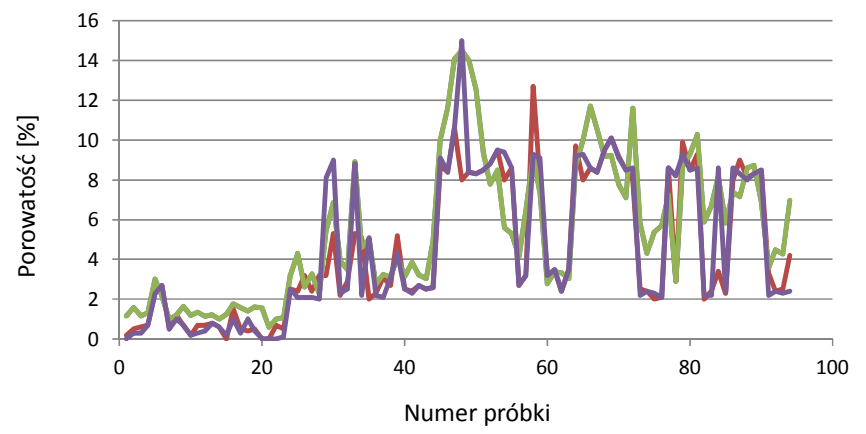

Rys. 12. Pełna baza danych wejściowych
Tablica 2. Wyniki korelacji

\begin{tabular}{|l|c|c|}
\hline \multicolumn{1}{|c|}{ Typ zbioru } & Rysunek & $\begin{array}{c}\text { Współczynnik } \\
\text { korelacji }\end{array}$ \\
\hline Bez średnicy progowej & 8 & 0,862 \\
\hline Bez powierzchni właściwej & 9 & 0,857 \\
\hline Bez histerezy & 10 & 0,853 \\
\hline Bez $\Delta$ gęstości & 11 & 0,843 \\
\hline Całość & 12 & 0,880 \\
\hline
\end{tabular}

wyliczonej. Współczynnik korelacji wskazuje wielkość wpływu danego parametru na porowatość. Wyniki przedstawiono w postaci wykresów (rysunki 8-12) i korelacji w tablicy 2.

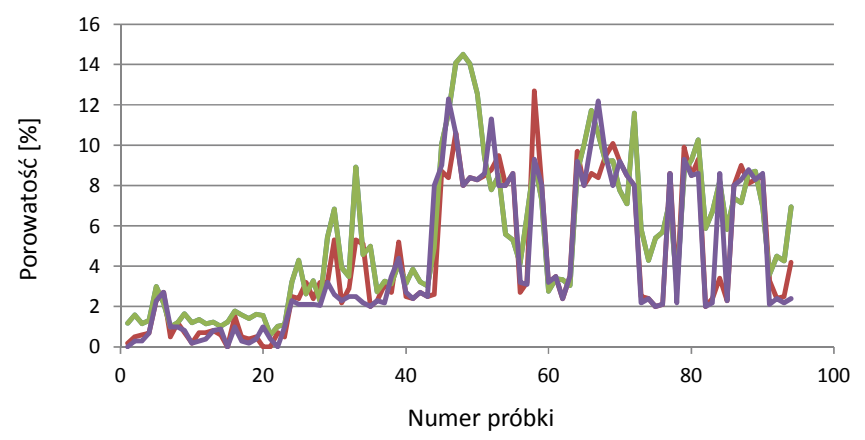

Rys. 9. Baza danych wejściowych z wykluczeniem powierzchni właściwej

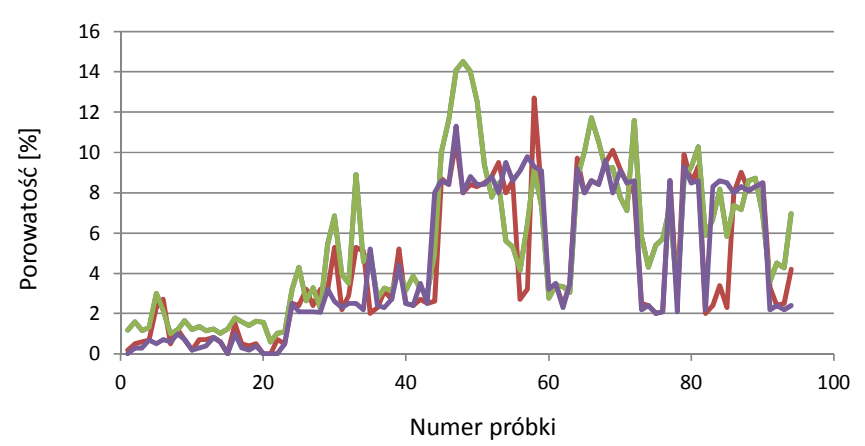

Rys. 11. Baza danych wejściowych z wykluczeniem $\Delta$ gęstości

Najlepszy wynik uzyskano w przypadku zastosowania wszystkich parametrów (rysunek 12, współczynnik korelacji 0,880 ). Po wykluczeniu ze zbioru obliczeniowego danego parametru korelacja zmniejsza się (tablica 2), największy wpływ na porowatość ma różnica gęstości szkieletowej i objętościowej oznaczona jako $\Delta$ gęstości. 


\section{Wnioski}

Z przedstawionych danych wynika, że wykonane symulacje metodą logiki rozmytej dobrze odzwierciedlają rzeczywiste trendy, dając dobrą korelację z wynikami rzeczywistymi. Jednakże na rysunkach można zauważyć zawyżenie danych w przypadku dużych wartości i zaniżenie w przypadku wartości średnich. Odchylenia wynikają ze zgrubnego dobrania lingwistycznych zbiorów oraz dość prostej formuły wyostrzania, czyli metody ostatniego maksimum. Metoda logiki rozmytej okazała się użyteczna, rzucając nowe światło na hierarchię wpływów parametrów przestrzeni porowej na porowatość, niemniej jednak wymaga dalszego dopracowania.

Prosimy cytować jako: Nafta-Gaz 2016, nr 6, s. 387-392, DOI: 10.18668/NG.2016.06.01

Artykuł nadesłano do Redakcji 23.12.2015 r. Zatwierdzono do druku 10.03.2016 r.

\section{Literatura}

[1] Darłak B., Kowalska-Włodarczyk M.: Próba zastosowania logiki rozmytej do interpretacji parametrów petrofizycznych skat zbiornikowych. Nafta-Gaz 2007, nr 5, s. 305-413.

[2] Darłak B., Kowalska-Włodarczyk M.: Zastosowanie logiki rozmytej w budowie modeli geologicznych. Nafta-Gaz 2009, nr 6, s. 454-461.

[3] Finol J., Jing X. D.: Permeability prediction in shaly formations: the fuzzy modeling approach. Geophysics 2002, vol. 67, no. 3, s. 817-829.

[4] Finol J., Jing X. D.: Predicting Petrophysical parameters in a fuzzy environment. Soft computing for reservoir characterization and modeling. Physica-Verlag 2002, vol. 80, s. $183-218$.

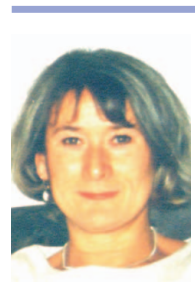

Mgr Barbara DARŁAK

Starszy specjalista badawczo-techniczny

w Zakładzie Geologii i Geochemii.

Instytut Nafty i Gazu - Państwowy Instytut Badawczy

ul. Lubicz 25 A

31-503 Kraków

E-mail: barbara.darlak@inig.pl
[5] Flasiński M.: Wstęp do sztucznej inteligencji. Warszawa, PWN, 2011, s. 195-205.

[6] Kisielewicz A.: Sztuczna inteligencja i logika. Warszawa, WNT, 2014, s. 228-249.

[7] Łęski J.: Systemy neuronowo-rozmyte. Warszawa, WNT, 2008.

[8] Piegat A.: Fuzzy modeling and control. Springer-Heidelberg, 2001, s. 1385-1390.

[9] Piegat A.: Modelowanie i sterowanie rozmyte. Warszawa, Akademicka Oficyna Wydawnicza EXIT, 1999.

[10] Rutkowska D., Piliński M., Rutkowski L.: Sieci neuronowe, algorytmy genetyczne i systemy rozmyte. Warszawa, PWN, 1997, s. 45-128.

[11] Zadeh L. A.: Fuzzy sets. Information and Control 1965, vol. 8, no. 3, s. 338-353.

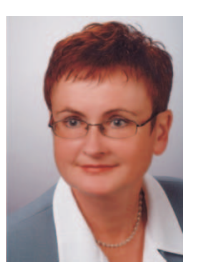

Mgr inż. Małgorzata KOWALSKA-

WŁODARCZYK

Starszy specjalista badawczo-techniczny

w Zakładzie Geologii i Geochemii.

Instytut Nafty i Gazu - Państwowy Instytut Badawczy

ul. Lubicz 25 A, 31-503 Kraków

E-mail: wlodarczyk@inig.pl 